\title{
Effect of acute immunoneutralization of inhibin in ewes during the late luteal phase of the oestrous cycle on ovarian hormone secretion and follicular development during the subsequent follicular phase
}

\author{
B. K. Campbell* and R. J. Scaramuzzi ${ }^{\dagger}$ \\ CSIRO Division of Animal Production, PO Box 239, Blacktown, NSW 2148, Australia
}

\begin{abstract}
Ewes with ovarian autotransplants received either inhibin antiserum (10 $\mathrm{ml}$ i.v.; $n=6)$ or sheep serum ( $10 \mathrm{ml}$ i.v.; $n=5$ ) on day 10 of the luteal phase with additional daily injections ( $1 \mathrm{ml}$ i.v.) from $48 \mathrm{~h}$ after the initial injection until the end of blood sampling, 9 days later. Luteal regression was induced by injection of prostaglandin $\mathrm{F}_{2 \alpha}\left(\mathrm{PGF}_{2 \alpha}\right) 4.2$ days after the initial plasma injection. Jugular and ovarian venous blood samples were taken every $4 \mathrm{~h}$ over the experimental period, and more frequent samples (every 10-15 min for 2-3 h) were taken to examine pulsatile secretory responses from the ovary to $\mathrm{GnRH}$-induced (150 ng i.m. 1 and 4 days after initial treatment) or endogenous LH pulses ( 24 and $48 \mathrm{~h}$ after injection of $\mathrm{PGF}_{2 \alpha}$ ). Plasma FSH concentrations, ovarian steroid secretion and ovarian follicular development were measured. Immunization against inhibin resulted in a two- to threefold increase $(P<0.001)$ in plasma FSH concentrations, which remained higher than controls until injection of $\mathrm{PGF}_{2 u}$. Within $24 \mathrm{~h}$ of immunization, there was an increase in the number of small ovarian follicles $(P<0.01)$ and by 4 days after treatment, immunized ewes had four or five $(P<0.01)$ large ovarian follicles and, despite little change in the basal steroid secretion, a four- to sixfold increase $(P<0.05)$ in the amplitude of the steroidogenic response to a GnRH-induced LH pulse. After induction of luteolysis, basal oestradiol and androstenedione secretion increased markedly to a preovulatory peak three- to fivefold higher $(P<0.01)$ than that of controls and occurring $24 \mathrm{~h}$ earlier $(P<0.001)$. As a result, the time of the preovulatory $\mathrm{LH}$ surge was also advanced $24 \mathrm{~h}$ in immunized ewes $(P<0.001)$. Induction of luteal regression by injecting $\mathrm{PGF}_{2 u}$ resulted in a decrease in FSH concentrations in both treatment groups, but this decrease was more marked in immunized animals $\left(50 \%\right.$ of value before $\mathrm{PGF}_{2 a}$ was given; $P<0.001$ ) than in controls $(20 \%$ of value before $\mathrm{PGF}_{2 a}$ was given; $P<0.05$ ), so that by $16 \mathrm{~h}$ after $\mathrm{PGF}_{2 \alpha a}$ injection, $\mathrm{FSH}$ values were no longer significantly different in the two treatment groups. This large fall in FSH concentrations had no deleterious effects on steroid secretion or the number of large follicles in immunized ewes and, as shown by a marked increase in ovarian size and a threefold increase $(P<0.001)$ in progesterone concentration during the subsequent luteal phase, these animals had multiple ovulations. We conclude that oestradiol alone can modulate FSH within physiological limits in the absence of inhibin negative feedback during the follicular phase and that the increase in ovulation rate that occurs after inhibin immunization is not caused by attenuation of the follicular phase suppression in FSH.
\end{abstract}

\section{Introduction}

In sheep, the number of follicles that develop to an ovulatory size depends on both the amount of FSH and the time of exposure to FSH (Picton et al., 1990; McNeilly et al., 1991). The release of FSH by the pituitary is in turn controlled by the

Present addresses *Department of Obstetrics and Gynaecology, University of Edinburgh, Centre for Reproductive Biology, 37 Chalmers St, Edinburgh $\mathrm{EH} 3 \mathrm{9EW}$, UK; and ${ }^{\dagger} \mathrm{The}$ Royal Veterinary College, University of London, Royal College Street, London, NWI OTU, UK.

Received 28 March 1995. synergistic action of two of the major products of ovulatory follicles: inhibin and oestradiol (Martin et al., 1988; Mann et al., 1992). On the basis of the pattern of secretion of these two hormones and their follicular origin, it has been postulated that inhibin maintains a tonic level of control over FSH secretion, while oestradiol modulates the marked fluctuations in peripheral FSH concentrations that occur throughout the oestrous cycle (Baird et al., 1991). The fall in blood FSH concentrations that occurs following luteal regression is the most important of these changes, as it has been proposed that dominance of the ovulatory follicle(s) is maintained by suppression of circulating 
concentrations of FSH during the follicular phase of the oestrous cycle in response to increased secretion of oestradiol or inhibin by the ovulatory follicle(s), which is sufficiently mature to have become relatively independent of FSH (Baird, 1983). The mechanism by which the preovulatory follicle can withstand this fall in FSH concentration is unclear, but Campbell et al. (1993) showed that these follicles remain critically dependent upon FSH for gonadotrophic support unless $\mathrm{LH}$ is provided in a pulsatile regimen of frequent low amplitude pulses that mimics the normal follicular phase pattern of LH secretion. While it is clear that the fall in FSH concentration that occurs after luteal regression is due mainly to the marked increase in LH-stimulated oestradiol secretion (Campbell et al, 1990a), the relative importance of inhibin is less certain, as secretion of inhibin also increases at this time (Campbell et al., 1990b) and immunization against inhibin during the follicular phase results in an increase in plasma FSH concentrations (Mann et al., 1990).

We have developed a model system designed to clarify the effect of immunization against inhibin on circulating $\mathrm{FSH}$ concentrations and ovarian function: ewes with an autotransplanted ovary are treated with a bolus of inhibin antiserum and with smaller supplementary injections of inhibin antiserum daily thereafter (Campbell et al., 1995). This immunization protocol is designed to combine the advantages of both passive and active immunization; the use of ewes with ovarian autotransplants allows the morphological and endocrine responses of the ovary to immunization to be assessed simultaneously. Passive immunization during the early luteal phase results in the expected acute response in $\mathrm{FSH}$, but maintenance of the anti-inhibin titre results in increased peripheral FSH concentrations for about 6 days after immunization, which in turn results in a marked stimulation of ovarian follicle development and steroid secretion (Campbell et al., 1995). However, when inhibin titres are maintained, the increase in ovulatory follicle development is sustained even after FSH concentrations in immunized ewes have returned to control values. These results suggest that, although the initial stimulatory effects of immunization can be attributed to increased $\mathrm{FSH}$, inhibin immunization stimulates ovarian function in the long term by interfering with the intraovarian modulation of follicle development by inhibin. An intraovarian role for inhibin, in addition to its endocrine role, has been postulated on the basis of a number of studies in vitro in humans (Hillier $e t$ al. 1991), rats (Findlay et al., 1990) and sheep (Campbell and Webb, 1995).

Such a dual endocrine and autocrine/paracine role for inhibin would help explain the observation that active immunization against inhibin, or its subunits, results in marked increases in ovulation rate in both sheep (O'Shea et al., 1989; Findlay et al., 1990; Wrathall et al., 1990, 1992) and cattle (Glencross et al., 1992; Morris et al., 1993), without the marked increases in circulating FSH concentrations (O'Shea et al., 1989; Findlay et al., 1990; Wrathall et al., 1990, 1992; Glencross et al., 1992, 1994) observed after passive immunization (Mann et al., 1990, 1992, 1993; Campbeil et al., 1995). An alternative explanation for the effect of inhibin immunization on ovulation rate is that immunization results in changes in the pattern of FSH secretion, particularly before and during luteolysis, rather than changes in the absolute concentration of FSH. Interference with inhibin feedback during the follicular phase may attenuate the magnitude of the fall in plasma FSH concentrations that occurs after luteolysis, and this could limit the ability of dominant follicles to suppress the development of follicular cohorts, and lead to an increase in ovulation rate.

The aim of the present study was to clarify the effects of immunoneutralization of inhibin during the follicular phase on the pattern of FSH secretion and ovarian function, using the model system, described above, which involves repeated passive immunization of ewes with ovarian autotransplants.

\section{Materials and Methods}

\section{Experimental animals}

The experiment was performed during the breeding season (June) at the CSIRO Division of Animal Production, Blacktown, NSW, using Border Leicester cross Merino ewes ( $n=11$; mean mass $66 \pm 1 \mathrm{~kg}$ ). Six months before the start of the experiment, the right ovary was removed and the left ovary and its vascular pedicle were autotransplanted to a previously prepared skin loop in the neck containing the right carotid artery and jugular vein (Goding et al., 1967). As ewes with ovarian autotransplants do not cycle spontaneously, oestrous cycles were synchronized by treatment with cloprostenol, an analogue of prostaglandin $\mathrm{F}_{2 \alpha}\left(\mathrm{PGF}_{2 a}\right.$ : $125 \mu \mathrm{g}$ i.m.; Estrumate, Cooper's Animal Health Ltd, Crewe, Cheshire), every 14 days. Oestrus was detected by a ram fitted with a marking harness (Radford et al., 1960). The sheep were housed under natural lighting and fed a maintenance diet of $600 \mathrm{~g}$ daily of a pelletted ration of $60 \%$ lucerne and $40 \%$ oats. On the day before the start of blood sampling, all animals had cannulae inserted into both jugular veins as described by Campbell et al. (1995) and were placed in metabolism crates under natural lighting in temperature-controlled rooms $\left(20^{\circ} \mathrm{C}\right)$. After cannulation, and daily thereafter, all animals received injections of antibiotics (4 ml i.m.; Hydropen ${ }^{*}$, Bomac Laboratories, Castle Hill, NSW) and, over the blood sampling period, 5000 iu heparin (Fisons Pharmaceuticals, Castle Hill, NSW) every $12 \mathrm{~h}$.

\section{Inhibin antiserum}

The antiserum used was the same material shown to be capable of stimulating sustained increases in circulating FSH concentrations (Campbell et al., 1995). The antiserum was raised in sheep to the fusion protein of the entire recombinant human $\alpha$ subunit of inhibin for the primary immunization, and human recombinant $32 \mathrm{kDa}$ dimeric inhibin (Tierney et al., 1990) for the booster immunization.

\section{Experimental design}

On day 10 of the luteal phase, the animals received either inhibin antiserum ( $10 \mathrm{ml}$ i.v.; $n=6$ ) or nonimmune sheep serum (10 $\mathrm{ml}$ i.v.; $n=5$ ) with additional daily injections ( $1 \mathrm{ml}$ i.v.) from $48 \mathrm{~h}$ after the initial bolus injection until the end of blood sampling. On day 14 of the oestrous cycle, 4.2 days after immunization, luteal regression was induced in all ewes by 
injections of $\mathrm{PGF}_{2 \alpha}$. Jugular $(4 \mathrm{ml})$ and ovarian $(5 \mathrm{ml})$ venous blood samples were taken every $4 \mathrm{~h}$ for 9.5 days, from $12 \mathrm{~h}$ before initial immunization to 5 days after injection of $\mathrm{PGF}_{2 \alpha}$ (day 3 of the cycle). In addition, there were four periods of more frequent sampling to examine pulsatile secretory responses from the ovary to $\mathrm{LH}$. The first two of these examined the response to a $\mathrm{GnRH}$ induced (150 ng i.v.) LH pulse and were conducted $\mathrm{I}$ and 4 days (just before $\mathrm{PGF}_{2 \alpha}$ injection) after the initial bolus serum injection, and involved collection of ovarian and jugular venous blood at intervals of $15 \mathrm{~min}$ or a total of $2.5 \mathrm{~h}$. The second two periods of intensive blood sampling examined the pulsatile response of the ovary to endogenous LH pulses, and were conducted $I$ and 2 days after $\mathrm{PGF}_{2 \alpha}$ injection. These involved collection of ovarian and jugular venous blood at intervals of $10 \mathrm{~min}$ for a total of $3 \mathrm{~h}$. The blood was centrifuged at $2500 \mathrm{~g}$ for $30 \mathrm{~min}$ at $4^{\circ} \mathrm{C}$ and the plasma stored at $-20^{\circ} \mathrm{C}$ until analysis. To allow calculation of ovarian hormone secretion rates, all samples of ovarian venous blood taken every $4 \mathrm{~h}$ and samples of ovarian venous blood taken every hour during intensive sampling periods, were timed. After correcting for the haematocrit (Collett et al., 1973), the rate of ovarian secretion was calculated.

\section{Ovarian scanning procedure}

The ovarian follicle population was examined daily using a combined sector real time ultrasound scanner with a sector $7.5 \mathrm{MHz}$ transducer probe (Ausonics, Lane Cove, NSW) as described by Campbell et al. (1994). The diameters of the antral cavity and position of all follicles greater than $2 \mathrm{~mm}$ in diameter were noted.

\section{Hormone assays and antibody titres}

Plasma concentrations of $\mathrm{LH}, \mathrm{FSH}$, androstenedione (Campbell et al., 1990c), oestradiol and progesterone (Campbell et al., 1994) were determined using previously described radioimmunoassays. The sensitivity of the assays for $\mathrm{LH}, \mathrm{FSH}$, androstenedione, oestradiol and progesterone were $0.2 \mu \mathrm{g}$ NIH-LH-S2O $\mathrm{I}^{-1}, 0.1 \mu \mathrm{g}$ NIAMDD-FSH-RPI I $\mathrm{I}^{-1}, 20 \mathrm{ng}$ androstenedione $1^{-1}, 15 \mathrm{ng}$ oestradiol $\mathrm{l}^{-1}$ and $0.2 \mu \mathrm{g}$ progesterone $1^{-1}$, respectively. The intra- and interassay coefficients of variation for $\mathrm{LH}, \mathrm{FSH}$, androstenedione, oestradiol and progesterone were 4.3 and $5.4 \%, 1.7$ and $2.8 \%, 6.2$ and $9.1 \%$, 6.4 and $10.2 \%$, and 7.9 and $10.0 \%$, respectively.

The ability of serum to bind iodinated peptide, corresponding to the first 26 amino acids of the $\alpha$ subunit of pig inhibin was determined using the methodology of Campbell et al. (1995).

\section{Statistical analyses}

Statistical analysis of hormonal profile data was conducted by repeated measures analysis of variance on log-transformed data (ANOVA). The parameters of pulsatile $\mathrm{LH}$, oestradiol and androstenedione secretion were determined using the Munro pulse analysis program (Zaristow Software, West Morham, Haddington, East Lothian) and comparisons between and within treatment groups were made by ANOVA on log- transformed data. In addition, the mean oestradiol and androstenedione secretion rate for each period of intensive blood sampling was determined and comparisons between and within treatment groups were made by ANOVA. Data from the final period of intensive blood sampling, collected $48 \mathrm{~h}$ after luteal regression, were not subjected to analysis, as many of the immunized animals had initiated a preovulatory LH surge by this time. A preovulatory $\mathrm{LH}$ surge was defined as having occurred when two consecutive samples had LH concentrations greater than $10 \mathrm{ng} \mathrm{ml}^{-1}$. Comparison between groups on the time of the LH surge was made by unpaired $t$ test. The ovarian follicle population was classified on the basis of diameter (small, 2-3.5 mm diameter; and large, $\geq 3.5 \mathrm{~mm}$ diameter) and treatment effects on the ovarian follicle population were determined by repeated sample ANOVA following $\sqrt{ }(x+0.5)$ transformation

\section{Results}

\section{Hormonal patterns}

Jugular venous hormone concentrations and antibody titres. Treatment of ewes with inhibin antiserum resulted in an acute increase $(P<0.001)$ in the ability of plasma to bind $\left[{ }^{125} \mathrm{I}\right]$ labelled p1-26 $\alpha$ inhibin (Fig. 1a). Although inhibin antibody titres remained higher than controls for the remainder of the experiment, antibody titres declined with time $(P<0.001)$, despite repeated injections of antiserum (Fig. Ia). Passive immunization against inhibin had no acute effect on plasma progesterone concentrations, and injection of $\mathrm{PGF}_{2 \alpha}$ on day 14 resulted in the expected decline $(P<0.001)$ in progesterone concentrations in both treatment groups (Fig. Ib). However, during the subsequent luteal phase, plasma progesterone values increased more rapidly in immunized animals and stabilized on day 6 at values three times higher than in controls $(P<0.001$; Fig. 1b).

Acute immunization against inhibin on day 10 of the luteal phase resulted in a two- to threefold increase $(P<0.001)$ in plasma FSH concentrations within $8 \mathrm{~h}$ of treatment (Fig. 2). Thereafter, mean jugular venous FSH concentrations remained relatively stable for about $36 \mathrm{~h}$ and then declined $(P<0.001)$ slowly over the following $60 \mathrm{~h}$. Despite this decline in the first 4 days after immunization, FSH concentrations in immunized animals remained higher than those in controls $(P<0.001)$. Over this period, mean jugular venous FSH concentrations in control animals did not vary with time $(P=0.98)$. Induction of luteal regression by injection of $\mathrm{PGF}_{2 u}$ resulted in a decrease in FSH concentrations in both treatment groups, but this decrease was more marked in immunized animals $(50 \%$ of pre-PGF $2 u$ value; $P<0.001$ ) than in controls $(20 \%$ of pre-PGF $2 u$ value; $P<0.05)$ with the result that, by $16 \mathrm{~h}$ after $\mathrm{PGF}_{2 \alpha}$ injection, FSH concentrations were no longer significantly different in the two treatment groups. Plasma FSH concentrations continued to decline in immunized ewes until the time of the preovulatory FSH/LH surge, which occurred 24 h earlier in immunized ewes, with less variation between individuals $(42.1 \pm 1.6 \mathrm{~h}$ for immunized compared with $68.3 \pm 4.8 \mathrm{~h}$ in controls; $P<0.001$ ). In the $24 \mathrm{~h}$ after the FSH/LH surge, mean jugular venous FSH increased $(P<0.01)$ to concentrations similar to those observed 

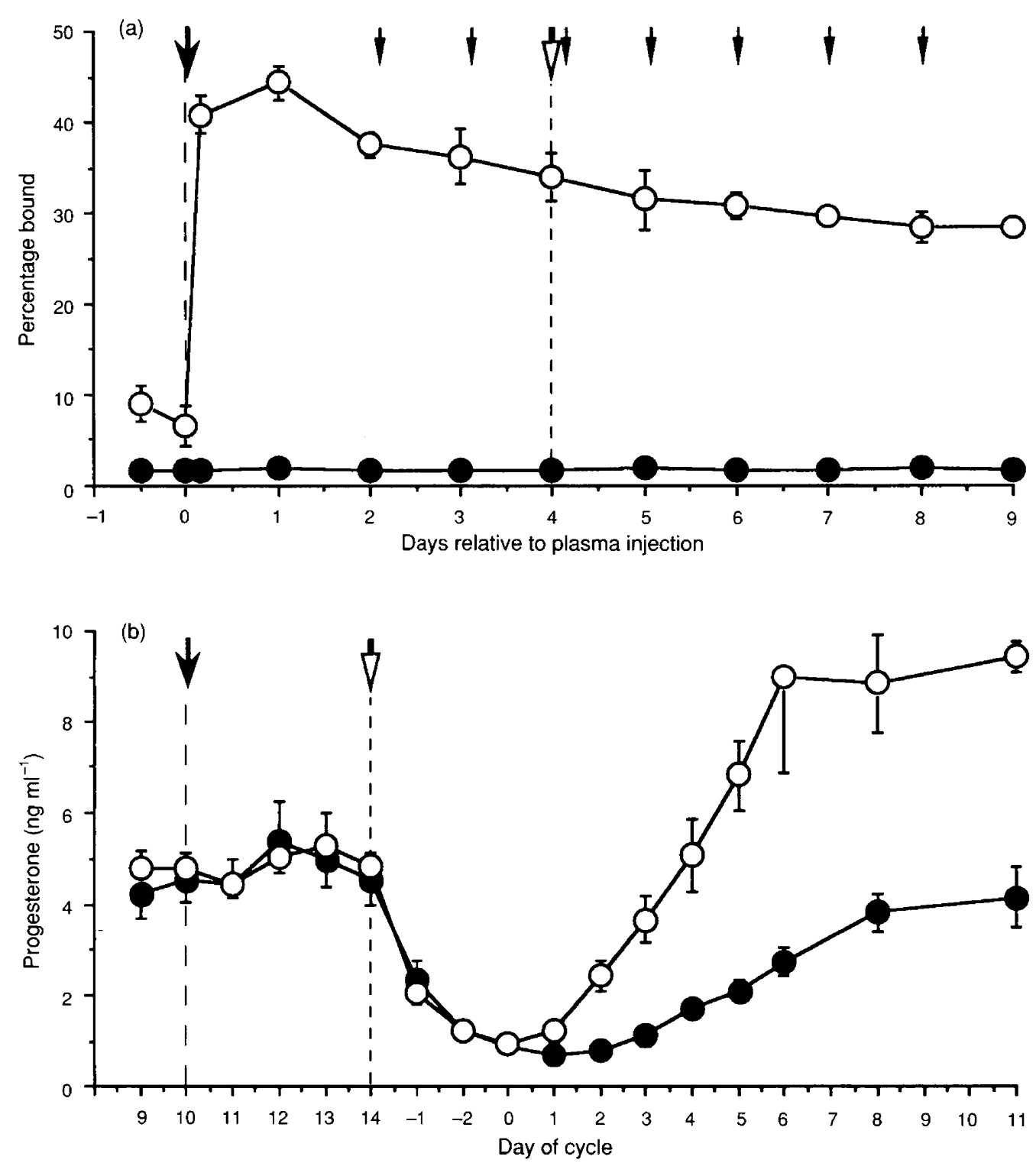

Fig. 1. Mean \pm SEM (a) inhibin antibody titres and (b) jugular venous progesterone concentrations in Border Leicester Merino ewes with an ovarian autotransplant that received either inhibin antiserum (10 ml i.v.; $n=6$; large solid arrow; $O$ ) or nonimmune sheep serum ( $10 \mathrm{ml}$ i.v.; $n=5$; large solid arrow; $)$ on day 10 of the luteal phase, with additional daily serum and antiserum injections ( $1 \mathrm{ml}$ i.v., small solid arrows) from $48 \mathrm{~h}$ after the initial bolus injection until the end of intensive blood sampling, 5 days after the induction of luteolysis by injection of $\mathrm{PGF}_{2 u}$ (open arrow).

before luteal regression, and remained stable for the remainder of the experimental period. Over this period, FSH concentrations in immunized animals were higher overall $(P<0.01)$ than in controls.

Basal LH concentrations did not change acutely after immunization, and LH concentrations remained similar in the two treatment groups until the time of luteal regression (data not shown). After injection of $\mathrm{PGF}_{2 \alpha^{\prime}}$ basal LH concentrations in controls increased with time $(P<0.001)$, but no such increase was observed in immunized ewes, with the result that, until the start of the advanced preovulatory surge, LH values were lower $(P<0.05)$ in immunized ewes than in controls. After the early $\mathrm{LH}$ surge observed in immunized ewes, basal $\mathrm{LH}$ values were higher $(P<0.01)$ in controls than in treated animals (data not shown). The parameters of pulsatile LH secretion determined during the periods of intensive sampling are presented in Table 1. LH pulse amplitude was higher $(P<0.05)$ in treated ewes $I$ day after passive immunization, was not different from controls 1 and 4 days after treatment, and was lower $(P<0.05)$ than controls during the early follicular phase, 5.2 days after immunization. In controls, there was no difference between days $I$ and 4 in the amplitude of GnRH-induced LH pulses, whereas in immunized ewes, LH pulse amplitude fell $(P<0.05)$ between days $I$ and 4 . In both treatment groups, the amplitudes of spontaneous follicular phase pulses on day 5.2 were lower than luteal phase GnRH-induced LH pulses on day 4, but 


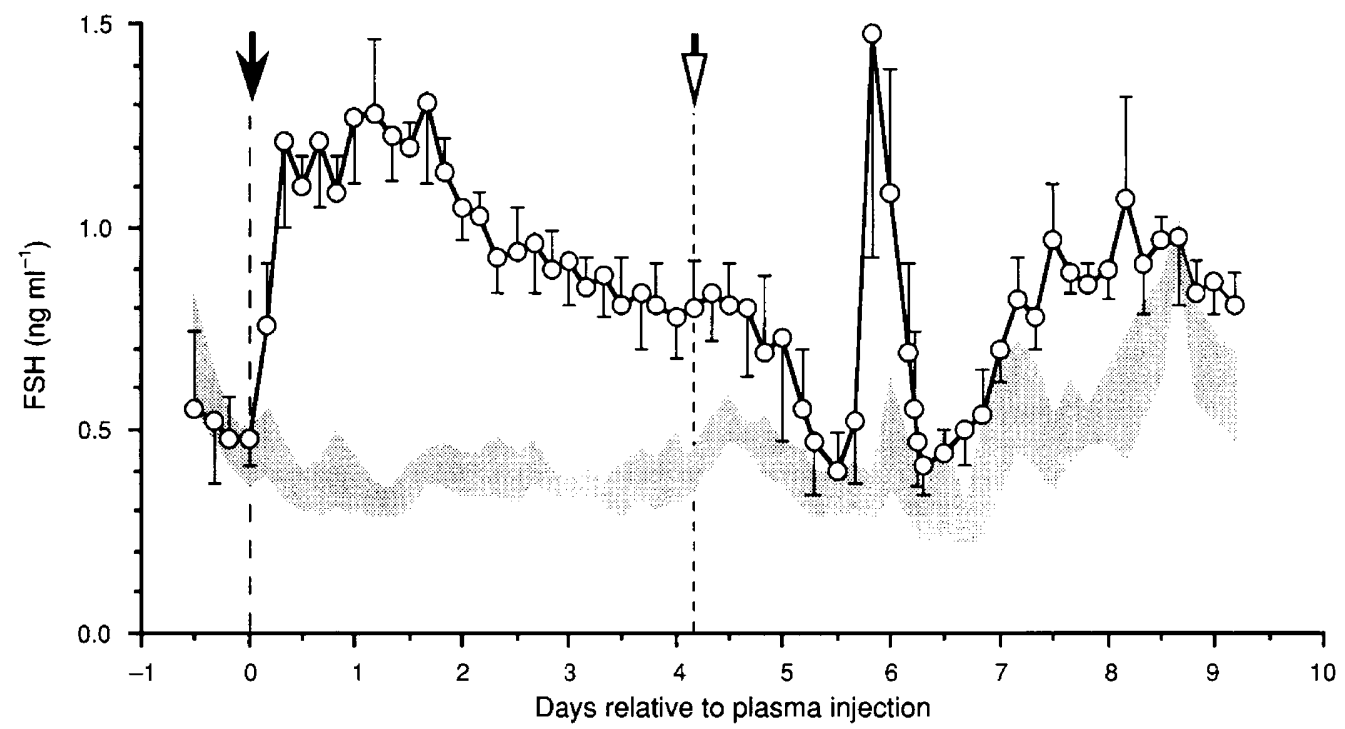

Fig. 2. Mean \pm SEM jugular venous concentrations of FSH in Border Leicester Merino ewes with ovarian autotransplants treated with either inhibin antiserum $(n=6$; solid arrow; $O)$ or nonimmune sheep serum $(n=5$; solid arrow; $\square$ ) on day 10 of the luteal phase (time 0 ), with additional daily serum and antiserum injections ( $1 \mathrm{ml}$ i.v.) from $48 \mathrm{~h}$ after the initial bolus injection until the end of intensive blood sampling 5 days after the induction of luteolysis by injection of $\mathrm{PGF}_{2 u}$ (open arrow).

the magnitude of this depression was much greater in treated ewes than in controls (Table 1). Pulse interval during the early follicular phase tended to be lower in immunized ( $45 \pm 10 \mathrm{~min})$ than in untreated $(71 \pm 8 \mathrm{~min})$ animals; this difference approached statistical significance $(P=0.09)$. There were no significant treatment or time effects on nadir LH values (Table $I$ ).

Ovarian oestradiol and androstenedione secretion. Before immunization there was no difference in basal steroid secretion in the two experimental groups. Within $24 \mathrm{~h}$ of treatment, the amplitude of the oestradiol response to a GnRH-induced $\mathrm{LH}$ pulse was increased $(P<0.05$; Table 1 and Fig. 3a) in immunized ewes and, by 4 days after treatment, the amount of oestradiol and androstenedione secretion was fivefold $(P<0.01)$ and twofold $(P<0.05)$ higher, respectively (Table 1 and Fig. 3) in immunized ewes than in controls. After the induction of luteal regression, control animals exhibited the normal pattern of ovarian steroid secretion (Campbell et al., $1990 \mathrm{~b})$ with a marked increase that reached a maximum just before the preovulatory $\mathrm{LH}$ surge, with negligible secretion thereafter. A similar pattern of secretion was observed in ewes immunized against inhibin, but the peak values in steroid secretion were four to five times higher $(P<0.01$; Fig. 3$)$ and occurred $24 \mathrm{~h}$ earlier. Examination of the pulsatile nature of steroid secretion, $24 \mathrm{~h}$ after induction of luteolysis, revealed that secretion was still pulsatile in immunized animals and that, despite the low LH pulse amplitude in treated ewes, the amplitude of the steroid response was five times higher $(P<0.05)$ in treated ewes than in controls (Table 1$).$

\section{Number of follicles}

Before treatment, both groups of ewes had ovaries containing, on average, $1-3$ small (2-3.5 mm diameter) and 1-2 large
( $>3.5 \mathrm{~mm}$ diameter) ovarian follicles. It was not possible to track the development of individual follicles accurately during this experiment owing to the speed and magnitude of the ovarian response to immunization. In control animals, the mean number of small or large follicles did not vary significantly over the time of the experiment (data not shown). In ewes immunized against inhibin, during the 2 days after treatment, the number of small, but not large, follicles increased fourfold (Fig. 4; $P<0.01$ ). Thereafter, the number of small follicles declined and the number of large follicles increased $(P<0.001)$ until, by the time of luteal regression, the ovaries of immunized ewes contained 4-5 large follicles, compared with I-2 large follicles in controls $(P<0.01)$. After induction of luteal regression, there was a tendency for the number of small follicles to decline and the number of large follicles to increase, but these trends were not significant. Nevertheless, by the time of the preovulatory $\mathrm{LH}$ surge, the ovaries of immunized ewes contained 6-7 large follicles per ewe.

During the subsequent luteal phase, the ovaries of the immunized ewes were 3-5 times their normal size. As scanning revealed that this was not due to follicular development, and the ovaries returned to their normal size after injection of $\mathrm{PGF}_{2 \alpha^{\prime}}$ this increase in ovarian size was attributed to multiple corpora lutea. The resolution of the scanner used in this experiment was insufficient to identify the number of corpora lutea accurately.

\section{Discussion}

The results of this experiment confirm and extend the observations of a preceding experiment in which ewes were passively immunized during the early luteal phase (Campbell et al. 1995). Maintenance of high circulating antibody titres to 
Table 1. Parameters of pulsatile LH, oestradiol and androstenedione secretion (mean \pm SEM) at different times after treatment of Border Leicester Merino ewes with ovarian autotransplants with either normal sheep serum ( $10 \mathrm{ml} ; n=5$ ) or inhibin antiserum ( $10 \mathrm{ml} ; n=6)$ given initially on day 10 of the luteal phase (time 0). Additional daily injections of serum or antiserum $(1 \mathrm{ml}$ ) were given on days $2-9$ after the initial bolus

\begin{tabular}{|c|c|c|c|c|}
\hline Treatment & $\begin{array}{l}\text { Time after } \\
\text { treatment }\end{array}$ & $\begin{array}{c}\text { Pulse } \\
\text { amplitude }\end{array}$ & Nadir & $\begin{array}{c}\text { Total } \\
\text { secretion }\end{array}$ \\
\hline \multicolumn{5}{|l|}{$\mathrm{LH}\left(\mathrm{ng} \mathrm{ml}{ }^{-1}\right)$} \\
\hline \multirow[t]{3}{*}{ Control } & Day $1(24-26.5 \mathrm{~h})$ & $1.5 \pm 0.3$ & $0.5 \pm 0.1$ & \\
\hline & Day $4(96-98.5 \mathrm{~h})$ & $2.2 \pm 0.4$ & $0.4 \pm 0.1$ & \\
\hline & Day $5.2(124-127 \mathrm{~h})$ & $1.1 \pm 0.3^{\dagger}$ & $0.6 \pm 0.1$ & \\
\hline \multirow[t]{3}{*}{ Immunized } & Day $1(24-26.5 h)$ & $4.1 \pm 0.8^{*}$ & $0.4 \pm 0.1$ & \\
\hline & Day $4(96-98.5 \mathrm{~h})$ & $1.9 \pm 0.4^{\dagger}$ & $0.4 \pm 0.1$ & \\
\hline & Day $5.2(124-127 \mathrm{~h})$ & $0.4 \pm 0.1^{* * \dagger}$ & $0.6 \pm 0.1$ & \\
\hline \multicolumn{5}{|c|}{ Oestradiol (ng $\min ^{-1}$ ) } \\
\hline \multirow[t]{3}{*}{ Control } & Day $1(24-26.5 \mathrm{~h})$ & $2.6 \pm 0.7$ & $0.7 \pm 0.4$ & $1.5 \pm 0.4$ \\
\hline & Day $4(96-98.5 \mathrm{~h})$ & $3.6 \pm 0.6$ & $1.2 \pm 0.6$ & $2.2 \pm 0.5$ \\
\hline & Day $5.2(124-127 \mathrm{~h})$ & $4.1 \pm 0.6$ & $2.1 \pm 1.0$ & $4.0 \pm 1.0$ \\
\hline \multirow[t]{3}{*}{ Immunized } & Day $1(24-26.5 \mathrm{~h})$ & $9.6 \pm 2.4^{*}$ & $0.7 \pm 0.2$ & $4.8 \pm 0.3^{*}$ \\
\hline & Day $4(96-98.5 \mathrm{~h})$ & $24.1 \pm 4.0^{* * \dagger}$ & $1.7 \pm 0.4$ & $11.9 \pm 2.3^{* *}$ \\
\hline & Day $5.2(124-127 \mathrm{~h})$ & $21.1 \pm 5.0^{*}$ & $12.2 \pm 3.3^{* \dagger}$ & $23.3 \pm 4.0^{*}$ \\
\hline \multicolumn{5}{|c|}{ Androstenedione $\left(\mathrm{ng} \min ^{-1}\right.$ ) } \\
\hline \multirow[t]{3}{*}{ Control } & Day $1(24-26.5 \mathrm{~h})$ & $7.3 \pm 0.6$ & $2.6 \pm 0.7$ & $5.6 \pm 1.0$ \\
\hline & Day $4(96-98.5 h)$ & $8.1 \pm 2.2$ & $4.0 \pm 0.6$ & $6.5 \pm 1.4$ \\
\hline & Day $5.2(124-127 \mathrm{~h})$ & $6.5 \pm 0.3$ & $2.2 \pm 0.8$ & $4.8 \pm 0.6$ \\
\hline \multirow[t]{3}{*}{ Immunized } & Day $1(24-26.5 \mathrm{~h})$ & $10.8 \pm 4.9$ & $3.0 \pm 0.8$ & $10.6 \pm 3.1$ \\
\hline & Day $4(96-98.5 \mathrm{~h})$ & $26.9 \pm 8.3^{*}$ & $3.8 \pm 1.1$ & $14.2 \pm 2.2^{*}$ \\
\hline & Day $5.2(124-127 \mathrm{~h})$ & $26.9 \pm 8.9^{*}$ & $8.3 \pm 1.6^{* \dagger}$ & $20.2 \pm 5.5^{*}$ \\
\hline
\end{tabular}

\footnotetext{
The parameters detailed describe either the LH response to a single bolus injection of $150 \mathrm{ng}$ of gonadotrophin-releasing hormone administered $30 \mathrm{~min}$ after the start of frequent blood sampling (days I and 4) or are derived from endogenous LH secretion determined $24 \mathrm{~h}$ after induction of luteolysis with $\mathrm{PGF}_{2 a}, 5.2$ days after serum injection. During this period, the pulse interval was $71 \pm 7.8 \mathrm{~min}$ and $45 \pm 9.6 \mathrm{~min}(P=0.09)$ for control and immunized ewes, respectively. Total secretion for oestradiol and androstenedione was calculated as the overall mean secretion rate for each period of intensive blood sampling.

${ }^{*} P<0.05,{ }^{*} P<0.01$; significantly different from control value at the same stage.

${ }^{+} P<0.05$; comparison within treatment groups, significant change in parameter with time.
}

inhibin during the late luteal phase in both studies resulted in a marked and sustained increase in plasma FSH concentrations which, in turn, led to the stimulation of ovarian follicle development and an increased capacity to secrete oestradiol and androstenedione when the ovary was stimulated by GnRH-induced LH pulses. In contrast to the previous study, the increase in LH pulse frequency, which occurs after induction of luteal regression, led to a marked increase in basal ovarian androgen and oestradiol secretion. This increase in oestradiol secretion is the probable cause of the rapid decline in plasma FSH concentrations (Mann et al., 1992), the depression in follicular phase LH pulse amplitude (Martin, 1984) and the $24 \mathrm{~h}$ advance in the time of the preovulatory LH surge (Martin, 1984) observed in immunized ewes after luteal regression. Furthermore, on the basis of the fivefold increase in the number of large follicles and the level of ovarian androstenedione and oestradiol secretion plus the threefold increase in progesterone concentrations in jugular venous blood during the following luteal phase, it is probable that the multiple follicles that developed before luteal regression continued to develop during the follicular phase and multiple ovulations resulted. This conclusion is supported by the large increase in ovarian size noted in immunized ewes during the subsequent luteal phase.

The acute fall in the concentration of FSH in jugular venous plasma that occurred in immunized ewes after luteolysis is of particular interest for a number of reasons. First, it reinforces the key role oestradiol has in the regulation of peripheral FSH concentrations, as oestradiol alone could suppress FSH to control concentrations in a situation in which inhibin feedback was blocked by immunoneutralization. This finding emphasizes the role that LH plays in the control of oestradiol secretion and hence peripheral FSH concentrations. Before luteolysis, the ovary could secrete appreciable quantities of oestradiol when stimulated by a GnRH-induced LH pulse, but basal oestradiol secretion at this time was low, presumably because $\mathrm{LH}$ pulse frequency was low (Baird and McNeilly, 1981), and FSH concentrations were raised. However, with the normal increase in LH pulse frequency that occurs after luteolysis, basal oestradiol secretion increased markedly and FSH concentrations fell. Although LH pulse amplitude was also suppressed by this increase in oestradiol secretion, the amplitude of the steroidogenic response to an $\mathrm{LH}$ pulse did not change between the luteal phase and the follicular phase in immunized ewes, 
(a)

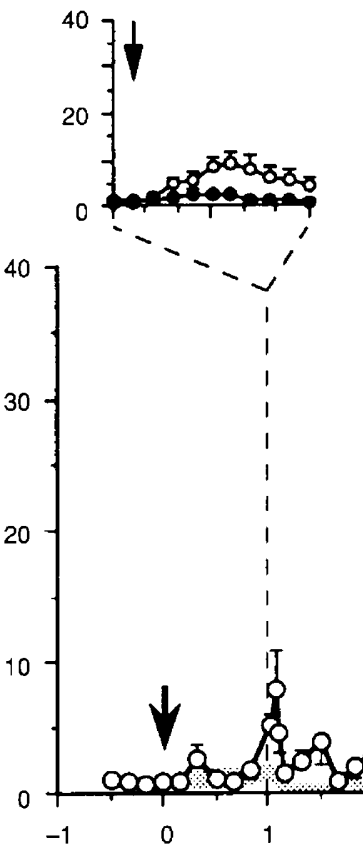

(b)
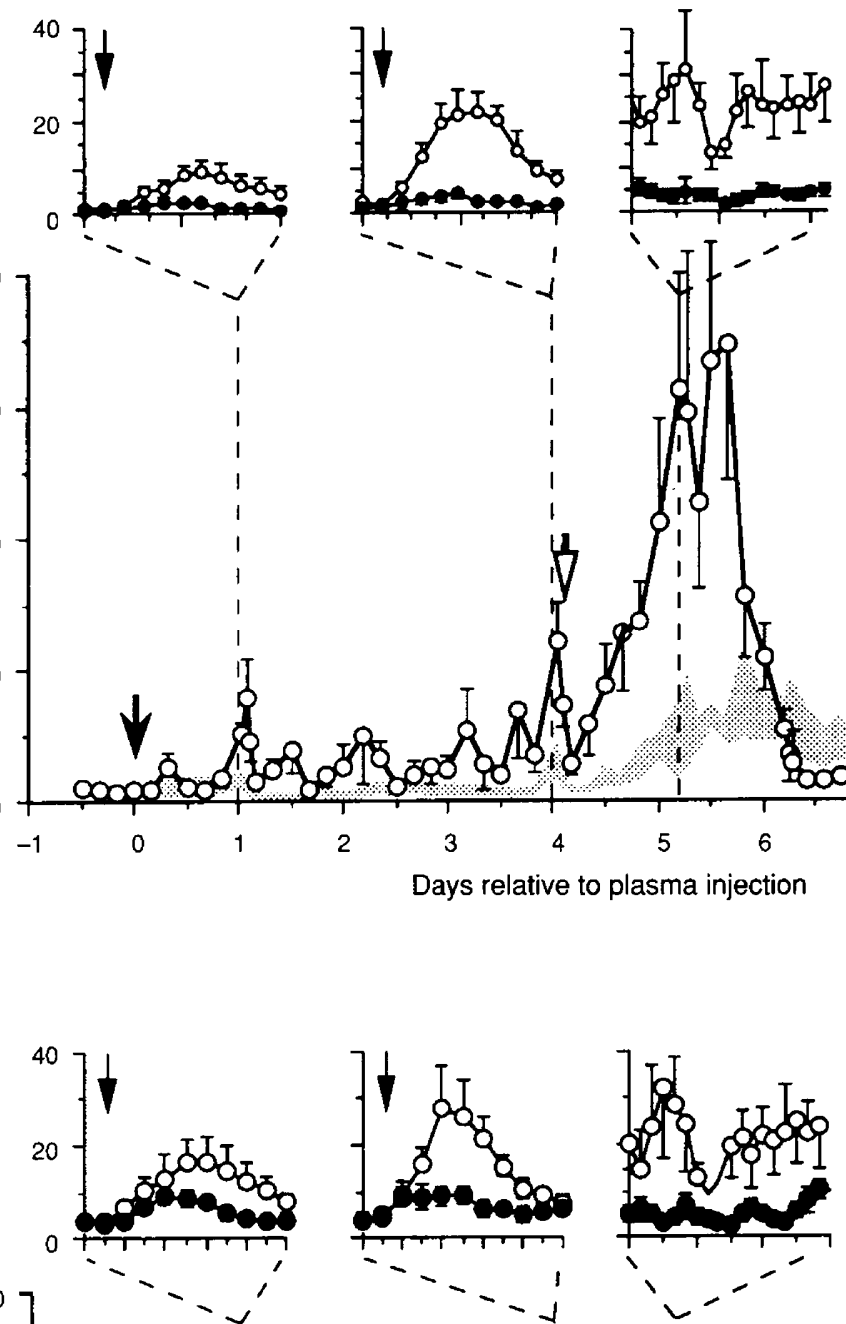

$\because$ If - -

19.

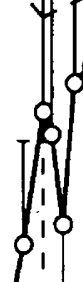

? 


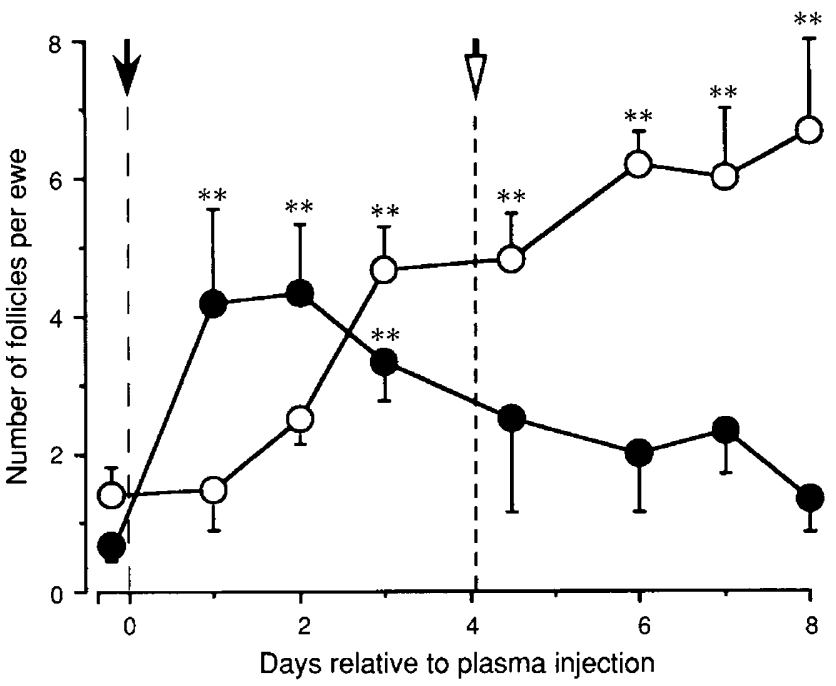

Fig. 4. Mean \pm SEM number of small (2-3.5 mm diameter; $)$ and large ( $\geq 3.5 \mathrm{~mm}$ diameter; $\bigcirc$ ) follicles per ewe, as determined by daily ultrasound scanning, in Border Leicester Merino ewes treated with inhibin antiserum $(n=6)$ on day 10 of the luteal phase (time 0 ), with additional daily serum and antiserum injections ( $1 \mathrm{ml}$ i.v.) from $48 \mathrm{~h}$ after the initial bolus injection until the end of intensive blood sampling, 5 days after the induction of luteolysis by injection of $\mathrm{PGF}_{2 a}$ (open arrow). Data from placebo-treated control ewes are not shown but, before treatment, both groups of ewes had ovaries containing 1-3 small and 1-2 large and, in control animals, the mean number of small or large follicles did not vary significantly with time over the period of the experiment. ${ }^{* *} P<0.01$; significantly different from number of same sized follicles before immunization.

indicating that the ovulatory follicles in the immunized ewes were extremely sensitive to $\mathrm{LH}$.

The acute fall in the peripheral concentration of FSH in immunized ewes is also of interest because oestrogenic follicles that developed under the influence of increased FSH could withstand an acute $50 \%$ fall in the amount of FSH support without any decrease in steroid secretion or the number of large follicles. The most probable means by which these follicles have apparently become independent of FSH support is by the transfer of their gonadotrophic requirements from FSH to LH. In a directly analogous situation, large oestrogenic follicles stimulated to develop by FSH infusion undergo atresia if FSH support is withdrawn, unless high frequency low amplitude LH pulses are given as FSH declines (Campbell et al., 1993). The magnitude of the depression in FSH that occurred after luteal regression in immunized ewes precludes the hypothesis that the increase in ovulation rate commonly observed in ewes actively immunized against inhibin is due to attenuation in the extent of the follicular-phase FSH suppression. This observation is supported by Mizumachi et al. (1990) who reported that the extent of the follicular phase depression in FSH is more marked in ewes actively immunized against inhibin, with high antibody titres and greatly increased ovulation rates (6-9). The fact that the large increase in oestradiol secretion observed in immunized ewes could suppress FSH to control concentrations provides a mechanism whereby raised concentrations of FSH may not be observed in inhibin immunized animals.
From the results of the present experiment, little can be concluded on the hypothesis that inhibin immunization may affect ovarian function by modulating the autocrine or paracrine actions of inhibin. However, it was shown that, steroidogenically, the follicles of immunized ewes appeared to be particularly sensitive to LH. Inhibin has been shown to augment LH-stimulated androstenedione production by cultured sheep thecal cells and FSH-stimulated oestradiol production by cultured sheep granulosa cells (Campbell and Webb, 1995). Although clearly able to inhibit the endocrine activity of inhibin, it is unlikely that the modest antibody titres obtained from passive or active inhibin immunization could block intrafollicular inhibin activity. Indeed, it is likely that intrafollicular inhibin concentrations are increased by immunization, as steroid immunization has been found to lead to an increase in intrafollicular steroid concentrations as well as ovarian secretion (Nieschlag and Wickings, 1978; Campbell et al., 1990c). Such a scenario would explain how immunization against inhibin could lead to increases in ovarian sensitivity to gonadotrophins.

While the passive immunization protocol used in this experiment was devised to study the physiological response of the hypothalamo-pituitary-ovarian axis to immunization against inhibin, the immunization regimen would appear to be in itself a practical means to obtain increases in ovulation rate in domestic ruminants. Such increases in ovulation rate are obtainable, using this regimen, without the use of exogenous gonadotrophins and without the problems of variability in antibody response commonly observed when animals are actively immunized. Whether this passive immunization regimen would overcome the problem of variability in ovulation rate response would need to be the subject of further investigation using a larger number of animals.

In conclusion, this experiment demonstrates that the maintenance of high circulating antibody titres to inhibin during the late luteal phase of the sheep oestrous cycle results in a marked increase in peripheral FSH concentrations that stimulates a four- to fivefold increase in the number of large oestrogenic follicles. In addition, despite a $50 \%$ decrease in FSH concentrations after the induction of luteal regression, immunization results in a three- to fivefold increase in basal oestradiol and androstenedione secretion, an advance in the time of the LH surge, and multiple ovulation with the subsequent establishment of a normal luteal phase. These results indicate that oestradiol alone can modulate FSH within physiological limits in the absence of inhibin negative feedback, and that inhibin immunization does not lead to an increase in ovulation rate by attenuation of the magnitude of the follicular phase suppression in FSH.

The authors acknowledge the help of J. A. Downing in the preparation of the ovarian autotransplants and the technical assistance of B. M. Gordon, D. Fahmiyan and R. Newman. They thank C. Tsonis and Biotechnology Australia Ltd for donation of the inhibin antiserum and the NIAMDD for donation of the reagents for the gonadotrophin radio-immunoassays. This work was supported by Australian Wool Corporation grant CPB5I and B. K Campbell was supported by a National Research Fellowship from the Australian Research Council. 


\section{References}

Baird DT (1983) Factors regulating the growth of the preovulatory follicle in the sheep and human Journal of Reproduction and Fertility 69 343-352

Baird DT and McNeilly AS (1981) Gonadotrophic control of follicular development and function during the oestrous cycle of the ewe journal of Reproduction and Fertility Supplement 30 119-133

Baird DT, Campbell BK, Mann GE and McNeilly AS (1991) Inhibin and oestradiol in the control of FSH secretion in the sheep Journal of Reproduction and Fertility Supplement 43 125-138

Campbell BK and Webb RW (1995) Evidence that inhibin has paracrine and autocrine actions in controlling ovarian function in sheep journal of Reproduction and Fertility Abstract Series 15 Abstract 140

Campbell BK, McNeilly AS, Picton HM and Baird DT (1990a) The effect of a potent $\mathrm{Gn}-\mathrm{RH}$ antagonist on ovarian secretion of oestradiol, inhibin and androstenedione and the concentration of $\mathrm{LH}$ and FSH during the follicular phase of the sheep oestrous cycle Journal of Endocrinology 126 377-384

Campbell BK, Mann GE, McNeilly AS and Baird DT (1990b) The pattern of ovarian inhibin, estradiol and androstenedione secretion during the estrous cycle in the ewe Endocrinology 127 227-235

Campbell BK, Scaramuzzi RJ, Downing JA and Evans G (1990c) Steroid secretion rates and plasma binding activity in ewes with an ovarian autotransplant actively immunized against androstenedione Journal of Reproduction and Fertility 89 485-496

Campbell BK, Gordon BM, Dobson H and Scaramuzzi RJ (1993) The relative role of LH and FSH in the growth and maintenance of preovulatory follicles Journal of Reproduction and Fertility Abstract Series 11 Abstract 21

Campbell BK, Gordon BM and Scaramuzzi RJ (1994) The effect of ovarian arterial infusion of transforming growth factor $\alpha$ on ovarian follicle populations and ovarian hormone secretion in ewes with an autotransplanted ovary Journal of Endocrinology 143 I3-24

Campbell BK, Gordon BM, Tsonis CG and Scaramuzzi RJ (1995) The effect of acute immuno-neutralisation of inhibin in ewes during the early luteal phase of the oestrous cycle on ovarian hormone secretion and follicular development Journal of Endocrinology 145 479-490

Collett RA, Land RB and Baird DT (1973) The pattern of progesterone secretion by the autotransplanted ovary of the ewe in response to ovine luteinizing hormone Journal of Endocrinology 56 403-411

Findlay JK, Clarke IJ, Luck MR, Rodgers RJ, Shukovski L, Robertson DM, Klein R, Murray JF, Scaramuzzi RJ, Bindon BM, O'Shea T, Tsonis CG and Forage RG (1990) Peripheral and intragonadal actions of inhibin-related peptides Journal of Reproduction and Fertility Supplement 43 139-150

Glencross RG, Bleach ECL, McLeod BJ, Beard AJ and Knight PG (1992) Effect of active immunization of heifers against inhibin on plasma FSH concentrations, ovarian follicular development and ovulation rate Journal of Endocrinology $13411-18$

Glencross RG, Bleach ECL, Wood SC and Knight PG (1994) Active immunization of heifers against inhibin: effect on plasma concentrations of gonadotrophins, steroids and ovarian follicular dynamics during prostaglandin-synchronized cycles Journal of Reproduction and Fertility 100 599-605

Goding JR, McCracken JA and Baird DT (1967) The study of ovarian function in the ewe by means of a vascular autotransplantation technique Journal of Endocrinology 39 37-52
Hillier SG, Yong EL, Illingworth PJ, Baird DT, Schwall RH and Mason AJ (1991) Effect of recombinant inhibin on androgen synthesis in cultured human thecal cells Molecular and Cellular Endocrinology 75 RI-R6

Mann GE, Campbell BK, McNeilly AS and Baird DT (1990) Effects of passively immunizing ewes against inhibin and oestradiol during the follicular phase of the oestrous cycle Journal of Endocrinology 125 417-424

Mann GE, Campbell BK, McNeilly AS and Baird DT (1992) The role of inhibin and oestradiol in the control of FSH secretion in the sheep Journal of Endocrinology 133 381-391

Mann GE, Campbell BK, McNeilly AS and Baird DT (1993) Follicular development and ovarian hormone secretion following passive immunization of ewes against inhibin or oestradiol Journal of Endocrinology 136 225-233

Martin GB (1984) Factors affecting the secretion of luteinizing hormone in the ewe Biological Reviews 59 1-87

Martin GB, Price CA, Thiéry J-C and Webb R (1988) Interactions between inhibin, oestradiol and progesterone in the control of gonadotrophin secretion in the ewe Journal of Reproduction and Fertility 82 319-328

McNeilly AS, Picton HM, Campbell BK and Baird DT (1991) Gonadotrophic control of follicle growth in the ewe Journal of Reproduction and Fertility Supplement 43 177-186

Morris DG, McDermott MG, Diskin MG, Morrison CA, Swift PJ and Sreenan JM (1993) Effect of immunization against synthetic peptide sequences of bovine inhibin $\alpha$-subunit on ovulation rate and twin-calving in heifers Journal of Reproduction and Fertility $97255-261$

Mizumachi M, Voglmayr JK, Washington DW, Chen CL and Bardin CW (1990) Superovulation of ewes immunized against the human recombinant inhibin $\alpha$-subunit associated with increased pre- and postovulatory folliclestimulating hormone levels Endocrinology 126 1058-1063

Nieschlag E and Wickings EJ (1978) Biological effects of antibodies to gonadal steroids Vitamins and Hormones 36 165-202

O'Shea T, Bindon BM, Hillard MA, Piper LR, Findlay JK and Miyamoto K (1989) Increase in ovulation rate in Merino ewes after active immunisation with inhibin preparations obtained by immunoaffinity chromatography Reproduction, Fertility and Development $1347-355$

Picton HM, Tsonis CG and McNeilly AS (1990) FSH causes a time-dependent stimulation of preovulatory follicle growth in the absence of pulsatile LH secretion in GnRH agonist treated ewes Journal of Endocrinology 126 297-307

Radford HM, Watson RH and Wood GF (1960) A crayon and associated harness for the detection of mating under field conditions Australian Veterinary Journal 36 57-66

Tierney ML, Goss NH, Tomkins SM, Kerr DB, Pitt DE, Forage RG, Robertson DM, Hearn MTW and de Kretser DM (1990) Physicochemical and biological characterization of recombinant human inhibin A Endocrinology 1263268 3270

Wrathall JHM, McLeod BJ, Glencross RG, Beard AJ and Knight PG (1990) Inhibin immunoneutralization by antibodies raised against synthetic peptide sequences of inhibin $\alpha$ subunit: effects on gonadotrophin concentrations and ovulation rate in sheep Journal of Endocrinology 124 167-176

Wrathall JHM, McLeod BJ, Glencross RG, Beard AJ and Knight PG (1992) Effects of active immunization against a synthetic peptide sequence of the inhibin $\alpha$-subunit on plasma gonadotrophin concentrations, ovulation rate and lambing rate in ewes Journal of Reproduction and Fertility 95 175-182 